\section{The Effect of Ageism on the Digital Divide Among Older Adults}

\section{Carol C McDonough*}

Department of Economics, University of Massachusetts Lowell, Lowell, Massachusetts, USA

\begin{abstract}
Older adults as a group are on the negative side of the digital divide. The term "digital divide" not only identifies who uses the internet and who does not, but also gradations of digital exclusion, that is, the complexity, depth, and variety of internet use. Lower use rates of computers and the internet among older adults have important social and cost ramifications. As the internet becomes more integrated into everyday life, people who do not use the internet are more likely to become more disenfranchised and disadvantaged. The literature attributes the digital divide affecting older adults to internal characteristics of older adults, such as lower levels of computer literacy, technophobia, lack of perceived usefulness and physical and cognitive deficits. This paper reviews the literature on ageism and on technology adoption for older adults and expands the literature by discussing why ageism may also contribute to the digital divide among older adults.
\end{abstract}

Studies have shown that older adults tend to use the Internet less than younger people ${ }^{1}$. That is, older adults as a group are on the negative side of the digital divide. The term "digital divide" refers to the tendency for older adults to be less likely to use the internet than younger people, and for those older adults who do access the internet to do so less. Thus the digital divide not only identifies who uses the internet and who does not, but also gradations of digital exclusion, that is, the complexity, depth, and variety of internet use ${ }^{2}$.

Older adults as a group are not monolithic with respect to internet usage. Within the population of older adults, internet adoption rates

*Corresponding author: Carol C McDonough, Department of Economics, University of Massachusetts Lowell, Lowell MA 01854, USA, Tel: +1 9789342784 E-mail: Carol_Mcdonough@uml.edu

Citation: McDonough CC (2016) The Effect of Ageism on the Digital Divide Among Older Adults. J Gerontol Geriatr Med 2: 008.

Received: September 16, 2015; Accepted: January 26, 2016; Published: February 10, 2016 vary by age, ethnicity, education and income. However, within each demographic subcategory, older adults have lower rates of internet usage than younger people ${ }^{3}$.

While older adults are the fastest growing group of internet users, older adults have had a much lower initial usage rate. Between 2000 and 2013, the percentage of Americans using the internet rose from 50 percent to 86 percent, while internet usage among older adults rose from 14 percent to 59 percent ${ }^{4}$. Usage rates among older adults have now stabilized and one half of older adults who do not use the internet think that they are not missing out and do not intend to use the internet in the future ${ }^{5}$. Furthermore the wide spread use of smartphones among younger people has exacerbated the magnitude of the digital divide for older adults. While approximately two-thirds of all Americans use smartphones, only 27 percent of older adults do so $^{6}$.

Lower use rates of computers and the internet among older adults have important social and cost ramifications. As the internet becomes more integrated into everyday life, people who do not use the internet are more likely to become more disenfranchised and disadvantaged. This is particularly true in the workplace and for health care services. The internet is increasingly being used for health care delivery and monitoring. Moreover, there is evidence that computer and internet usage by older adults reduces the risk of depression?

The field of gerontechnology ${ }^{8}$ has emerged to study the multidisciplinary interplay between technology and successful aging. As $\mathrm{Wu}[10]$ points out, there are two categories of technology when discussing technology use among older adults: technology that targets the overall population and assistive technology, for older adults with special needs.

Bamidis et al., [11] successfully used computers to examine the effects of the dual-therapeutic interventions of physical and cognitive training. The Greek study enrolled 322 community-dwelling older adults ranging from cognitively healthy individuals to individuals with MCI (Mild Cognitive Impairment) or dementia. Earlier studies using mono-therapeutic interventions of physical and cognitive training showed task-and domain specific cognitive benefits, but limited generalization effects on global cognition. Using touch screen computer systems and on-site professional support personnel, Bamidis and Fissler found that combining physical and cognitive training can overcome this shortcoming. Their intensive short-term physical and cognitive training program induced benefits in global cognition, executive function and episodic memory. Their work illustrates the benefits that older adults can derive from using computers and the internet.

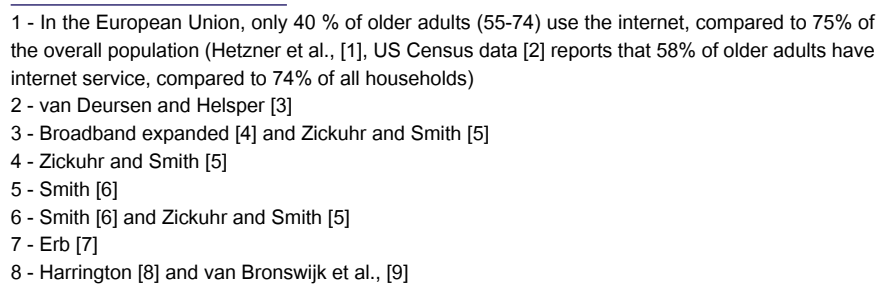


The literature attributes the digital divide affecting older adults to internal characteristics of older adults, such as lower levels of computer literacy ${ }^{9}$, technophobia ${ }^{10}$, lack of perceived usefulness ${ }^{11}$ and physical and cognitive deficits ${ }^{12}$. However the impact of an external factor, ageism, has not been explored. This paper reviews the literature on ageism and on technology adoption for older adults. The paper then expands the literature by discussing why ageism may contribute to the digital divide among older adults.

\section{Ageism}

Butler [15], who coined the term age-ism, defines age-ism as age discrimination, prejudice by one age group toward other age groups. According to Butler, age-ism describes "the subjective experience implied in the popular notion of the generation gap. Age-ism reflects a deep seated uneasiness on the part of the young and middle-aged-a personal revulsion to and distaste for growing old, disease, disability; the fear of powerlessness, uselessness and death". Butler [16] describes age-ism as a form of "systematic stereotyping and discrimination against people simply because they are old. Advertisements and greeting cards depict older persons as forgetful, dependent, childlike and sexless".

Palmore [17] developed a structure for the discussion of ageism, both positive and negative, at the individual, institutional and societal levels. According to Palmore, negative ageism (the type of ageism that we suggest has a negative effect on internet use) includes demeaning behaviors and/or discriminatory attitudes, such as telling a person that they are too old to learn something new. Palmore [18] reported that over 77 percent of survey respondents reported experiencing one or more incidents of ageism.

Keita, the American Psychological Association's (APA) executive director for the public interest [19], has stated that age prejudice is one of the most socially condoned and institutionalized forms of prejudice. The APA publications manual recommends the term "older adults" (the terms "elderly" and "senior" are not acceptable.) Studies using the Fraboni Scale ${ }^{13}$ and other measures ${ }^{14}$ reveal that ageism, referring to prejudice or discrimination based on perceived chronological age, is prevalent and detrimental to individuals and groups in society [21].

The Assisted Living Federation of America [22] defines ageism as a form of discrimination and prejudice, stating that societal norms marginalize seniors, treat them with disrespect, and make them feel unwelcome ${ }^{15}$.
Cartoons, and television and internet commercials, often depict older adults in a negative manner ${ }^{16}$. Neves [23] notes that the "elderly are commonly depicted as technophobic" and suggests that this characterization may be related to a preconception or a stereotype. Neves cites evidence of this stereotype in the popular culture, from a "plethora of cartoons to commercials and videos where the elderly and their use of computers are ridiculed".

Levy's [24] Stereotype Embodiment Theory describes how age stereotypes assimilated from the surrounding culture by younger people become self-definitions and self-stereotypes as we age, with a negative influence on functioning and health. Levy further notes that "old-age cues that prompt the transition of age stereotypes to self-relevance may be encountered on an interpersonal level, as in patronizing forms of speech directed at the old by the young. Cues may also be presented on an institutional level when older individuals are denied employment or appropriate medical treatment." As Cherry et al., [21] point out, whether intentional or unintentionally driven, ageism may have a detrimental impact on older adults' perceptions of their own competencies, as negative attitudes about aging become self-directed.

\section{Technology adoption}

While the literature on technology adoption does not include ageism, this literature is consonant with our hypothesis that ageism may contribute to the digital divide.

Foundations: Economists' work on the demand for products and services provides a foundation for the discussion of technology adoption. Economists assume that consumers make decisions that maximize their utility or satisfaction ${ }^{17}$ The concept of utility maximization is supported by introspective evidence that by and large our actions are geared to the goals we seek to achieve [25].

Becker [26] expanded the concept of utility maximization by acknowledging that monetary outlay may not be the only cost associated with the purchase and use of a product or service. Time costs and psychic costs may also enter into a consumer's decision. Psychic costs are a subset of social costs that specifically represent the costs of added stress or losses to quality of life. Psychic costs are related to the anxiety, embarrassment, and fear of failure associated with a product or activity. For older adults, there may be psychic costs associated with internet use. Several studies have identified anxiety

\footnotetext{
9 - Hetzner et al., [1], US Federal communications commission survey [12]

10 - Donat et al., [13]

11 - Porter et al., [14]

12 - Broadband Expanded [4]

13 - The Fraboni Scale of Ageism (FSA) is a 29-item scale that was developed to measure the affective and cognitive components of ageism. Sample items include "Complex and interesting conversations cannot be expected from most old people," "It is best that old people live where they won't bother anyone," and "I sometimes avoid eye contact with old people when I see them". 14 - Aosved et al., [20].

15 - ALFA cites the following examples: Late night comedians and talk show hosts joke about seniors and memory loss; Doctors often talk past the senior patient to an adult child as if the senior wasn't even in the room; Younger adults mock seniors for being "slow"; Commercial advertisements depict seniors as out of date, and lacking knowledge about modern culture and new technologies; Certain laws and regulations are paternalistic towards seniors and limit their choices.

16 - Cartoons may depict older adults as incompetent, forgetful, and computer and internet-challenged. (Seniors' Internet Please turn handle (Sangrea.net); I'm old enough to make my own decisions just not young enough to remember what I decided (Life as I see it. com). Two current auto commercials depict older women in a very unflattering way. (BMW X5 Leather Commercial www.youtube.com/watch?v=pNJ6TD2u5S0;VW Old Wives Tale www.youtube.com/ watch? $=8 Z h G p Z a L C 10)$.

17 - Utility is a subjective valuation of the benefit or usefulness of a product or service
} 


\begin{tabular}{|c|c|c|c|}
\hline Reference & Source & Purpose/Hypothesis & Results/Conclusions \\
\hline Bandura [32] & Psychological review & $\begin{array}{l}\text { Study if cognitive processes mediate change and if cognitive } \\
\text { events are induced and altered most readily by experience of } \\
\text { mastery arising from effective performance }\end{array}$ & $\begin{array}{l}\text { Study subjects showed performance high positive } \\
\text { correlation between self-efficacy and performance }\end{array}$ \\
\hline Czaja [27] & Psychology of aging & $\begin{array}{l}\text { Study the factors affecting use of technology among commu- } \\
\text { nity-dwelling adults aged } 18-91 \text {, using a structural regression } \\
\text { model }\end{array}$ & $\begin{array}{l}\text { The model accounted for } 64 \% \text { of the variance in } \\
\text { breadth of computer use, with direct paths from age, } \\
\text { computer anxiety, crystallized intelligence, computer } \\
\text { efficacy and use of technology. Computer self-effica- } \\
\text { cy was an important predictor of computer anxiety }\end{array}$ \\
\hline Davis [33] & MIS Quarterly & $\begin{array}{l}\text { Develop Technology Adoption Model (TAM) that models } \\
\text { behavior of information technology adoption in a work environ- } \\
\text { ment. Hypothesize that user's intent to use technology is influ- } \\
\text { enced by belief about perceived usefulness and ease of use }\end{array}$ & $\begin{array}{c}\text { Test results showed that perceived usefulness } \\
\text { was more significant than perceived ease of use in } \\
\text { explaining technology adoption }\end{array}$ \\
\hline Donat et al., [13] & Informing science & $\begin{array}{c}\begin{array}{c}\text { Estimate logistic regression model to study the determinants } \\
\text { of internet use }\end{array}\end{array}$ & $\begin{array}{c}\text { The model results showed that age had a significant- } \\
\text { ly negative effect on internet use. Older respondents } \\
\text { evaluated the internet more negatively than younger } \\
\text { respondents, especially for perceived difficulty, and } \\
\text { were more technophobic }\end{array}$ \\
\hline McDonough [35] & $\begin{array}{l}\text { Report for sustainable } \\
\text { broadband adoption, NTIA }\end{array}$ & Study reasons for internet use or non-use among older adults & $\begin{array}{l}\text { Among older adults who had never or rarely used } \\
\text { the internet prior to training, } 83 \% \text { of those who used } \\
\text { the internet post-training (or more often) reported } \\
\text { increased comfort as the reason for internet use }\end{array}$ \\
\hline Morris et al., [36] & Personnel psychology & $\begin{array}{l}\text { Extend Davis' work by examining the impact of age on tech- } \\
\text { nology adoption decisions in the workplace }\end{array}$ & $\begin{array}{c}\text { The results showed that older workers weighed } \\
\text { the importance of perceived social pressure and } \\
\text { perceived ease of use more strongly than younger } \\
\text { workers }\end{array}$ \\
\hline Parasuraman [37] & $\begin{array}{l}\text { Journal of service } \\
\text { research }\end{array}$ & $\begin{array}{l}\text { Develop Technology Readiness (TR) model to measure a } \\
\text { person's predisposition to use new technologies }\end{array}$ & $\begin{array}{l}\text { The study showed that optimism and innovativeness } \\
\text { increased technology use, while discomfort and } \\
\text { insecurity reduced internet use }\end{array}$ \\
\hline Porter et al., [14] & $\begin{array}{l}\text { Journal of business } \\
\text { research }\end{array}$ & $\begin{array}{c}\text { Extend TAM by introducing perceived access barriers and } \\
\text { demographic barriers as factors that might influence attitude } \\
\text { toward the internet }\end{array}$ & $\begin{array}{l}\text { Their study confirmed the importance of perceived } \\
\text { ease of use and perceived usefulness. They also } \\
\text { found that older adults have more negative beliefs } \\
\text { about the internet, which leads to negative attitudes } \\
\text { and reduced internet usage }\end{array}$ \\
\hline Zheng et al., [38] & Educational gerontology & $\begin{array}{l}\text { Conducted principal factor analysis to examine older adults' } \\
\text { perceptions of internet use }\end{array}$ & $\begin{array}{l}\text { Self-efficacy and social connection (which was shown } \\
\text { to be related to psychological well-being), were } \\
\text { significant determinants of older adults' perception of } \\
\text { internet use. }\end{array}$ \\
\hline
\end{tabular}

and fear of failure as reasons for the digital divide ${ }^{18}$. This is consistent with the finding that older adults tend to be risk averse ${ }^{19}$, or more risk-avoidant than younger people ${ }^{20}$.

Market researchers have framed the concept of consumer demand in terms of value consciousness. Consumer perceived value is defined as the consumer's overall assessment of the utility of a product based on perceptions of what is received and what is given [31].The perception of what is given relates to the monetary and non-monetary costs of the product, including psychic costs.

Research: Numerous researchers have contributed to the literature on technology and internet adoption. Table 1 summarizes these studies by author, source, purpose/hypothesis, and results/conclusions.

\section{Self-efficacy}

Bandura [39] introduced self-efficacy as an important factor in technology acceptance and use. Bandura defined self-efficacy as one's belief in one's ability to succeed in specific situations. The theory of self-efficacy lies at the center of Bandura's social cognitive theory, which emphasizes the role of observational learning and social experience in the development of personality, i.e., an individual's actions and reactions, including social behaviors and cognitive processes, are influenced by the actions that individual has observed in others. According to Bandura's theory, people with high self-efficacy-that is, those who believe they can perform well-are more likely to view difficult tasks as something to be mastered rather than something to be avoided.

Czaja's [27] study of the factors predicting the use of technology found that computer self-efficacy was an important predictor of technology use. Self-efficacy was a predictor of computer anxiety, an attitudinal variable negatively related to computer use. Czaja \begin{tabular}{l}
\hline 18 - Czaja [27], Wu et al., [10] \\
19 - Nielsen L et al., [28]; Rogers EM [29] \\
20 - Roalf et al., [30]
\end{tabular} 
acknowledged that cognitive and physical abilities do influence technology adoption ${ }^{21}$. However she found that there was a strong,

Independent effect of age on technology adoption not accounted for by attitudes and cognitive ability. Czaja reported that older adults had lower self-efficacy regarding computer use and more computer anxiety than younger adults. Moreover, computer self-efficacy has an indirect effect on technology adoption through anxiety, since people with lower self-efficacy have higher anxiety ${ }^{22}$.

Czaja's findings corroborate the earlier work of Ellis and Allaire [41], who had reported that age was negatively associated with computer knowledge and interest and positively associated with computer anxiety. Like Czaja, Ellis and Allaire also found that not all age-related variance in computer interest was explained by computer anxiety or computer knowledge. They concluded that other factors, such as self-efficacy beliefs, may be important in explaining age differences in computer interest. Similar findings had been reported by Brosnan [42], who found that self-efficacy predicted computer anxiety, which in turn predicted word processor use.

Zheng et al., [38] used survey data from over 300 community-dwelling older adults in a mid-size US urban area to examine the factors perceived by older adults as critical to internet use. With a principal factor analysis model, Zheng found that self-efficacy and social connection (which was shown to be related to psychological well-being) were significant determinants of older adults' perception of internet use.

\section{Technology acceptance model}

Davis' Technology Acceptance Model (TAM) [33] extended Bandura's work by modeling behavior of information technology adoption in a work environment. The data base was surveys of 112 employees of IBM Canada. TAM is system-specific and hypothesizes that user acceptance of new technology is determined by the user's intention to use the technology, which in turn is influenced by the user's belief about the technology's perceived usefulness and perceived ease of use. Perceived usefulness is defined as the extent to which a person believes that use of a particular technology will improve his/her performance. Perceived ease of use identifies a person's belief that using a particular technology will not be onerous or require great effort. Testing the TAM hypothesis within a work environment, Davis found that perceived usefulness was more significant than perceived ease of use in explaining technology use. "Workers are willing to cope with some difficulty of use in a system that provides critically needed functionality".

Expanding Davis' work, Morris and Venkatesh [36] examined the impact of age on technology adoption decisions in the workplace. The data base for this research was 130 customer account representatives in a medium-size United States mid-west accounting firm. Morris and Venkatesh assert that physical and cognitive issues may contribute to the tendency for older workers to be more technology-averse. However, they found that attitude toward technology, perceived social pressure to use technology, and perceived behavioral control (ease of use) were significant in explaining technology usage. They reported that older workers weighed the importance of perceived social pressure and perceived ease of use more strongly than younger workers.

While Davis', and Morris and Venkatesh's, research contributes to the discussion of the digital divide among older adults, the limitations of these studies are (1) they focused on technology adoption in the workplace, not among older adults who may be retired and (2) the studies were conducted when computers and the internet were in their infancy.

Several other researchers have also extended TAM. Venkatesh and Bala [43] included the effects of trust and perceived risk on user acceptance. Yu et al., [44] included individual differences, personal innovation, gender and age.

Porter and Donthu [14] extended TAM by introducing perceived access barriers and demographic barriers as factors that might influence attitude toward the internet. Their study not only confirmed the theoretical importance of perceived ease of use and perceived usefulness. They also found that perceived access barriers can influence consumer attitudes toward the internet and that age is associated differentially with attitudes toward the internet and thus internet use. That is, older adults have more negative beliefs about the internet, which leads to negative attitudes and reduced internet usage.

\section{Technology readiness}

Another approach to the study of technology adoption is Parasuraman's [37] Technology Readiness (TR). TR refers to a person's propensity to embrace and use new technologies for accomplishing goals in home life and in work. TR was developed to measure a person's predisposition to use new technologies. TR is comprised of four dimensions: optimism, innovativeness, discomfort and insecurity. Optimism means a positive view of technology and a belief that technology provides enhanced efficiency and control. Innovation means having a tendency to pioneer new technology. Discomfort means perceived lack of control and a feeling of being overwhelmed by technology. Insecurity refers to mistrust and skepticism of technology. Parasuraman found a positive relationship between technology use and innovation and optimism, and a negative relationship between technology use and discomfort and insecurity.

\section{Technology readiness and acceptance model}

Lin, Shih and Sher [34] integrated TAM and TR into what they labelled TRAM (Technology Readiness and Acceptance Model). According to the authors, TRAM augments TAM by bringing technology readiness into the technology adoption decision, specifically consumer adoption of e-services. TRAM applies to a non-work setting within which the consumer exhibits self-determining selection behavior. The TRAM model showed a chain of causality: from technology readiness to perceived ease of use and perceived usefulness and finally to intention to use technology. The TRAM findings imply that consumers who view themselves as technologically incompetent refuse or delay their adoption of technology by devaluating the benefits and usefulness of these services. That is, there

21 - Czaja [27] described that as part of the normal aging process, older adults may experience declines in eyesight and audition, and motor skills, which may make it difficult to use input devices such as a mouse or keyboard, or a small screen display. She also identified a number of age-related changes in cognitive abilities, such as working memory, attentional processes and spatial cognition and stated that these abilities decline with age, especially under conditions of complexity or when confronting new technology

22 - Supporting this finding is MacLeod's [40] observation that individuals who report high levels of anxiety often display performance deficits across a wide range of cognitive tasks. 
is a positive relationship between consumers' technology readiness and their perception of technology's usefulness.

\section{Survey results of internet use}

Umemuro's [45] survey of Japanese older adults revealed that more positive computer attitudes, especially regarding comfort and interest, were related to greater computer usage. Donat et al., [13] conducted telephone surveys of 529 Austrians regarding internet use or non-use. Estimating a logistic regression model, they found that age had a significantly negative effect on internet use. Older respondents evaluated the internet more negatively than younger respondents, especially regarding perceived difficulty, and were more technophobic. van Deursen and Helsper [3] surveyed 4414 Dutch older adults about internet use and non-use. This study is interesting because internet usage in the Netherlands is ubiquitous, at 97 percent of the population. 9.1 percent of respondents reported that they did not use the internet, and only 13 percent of non-users responded that they intended to use the internet in the future. Non-users with an internet connection at home reported an even lower rate $(7 \%)$ of intended internet use, perhaps because someone with whom they lived used the internet for them. 55 percent of these non-users provided reasons for non-use. A negative attitude toward the internet was a major reason for non-use. Non-users with more education were more likely to report not having enough time to use the internet. Older adults who lived with others were more likely to respond that they were too old to use the internet. Participants were not asked about comfort or anxiety levels associated with internet use.

McDonough's [35] surveys of pre-training and post-training internet usage among disadvantaged younger adults and older adults provide additional information. Approximately $50 \%$ of older adults ${ }^{23}$ in the training program had never or rarely used the internet prior to training. Using logit analysis, McDonough and Kingsley [46] found that, on average, being an older adult increased the probability of never having used the internet by 39 percent. Among older adults who had never or rarely used the internet pre-training, 83 percent of those who used the internet post-training (or used it more frequently) reported increased comfort level as the reason for internet use. Fifty-one percent of all older adults who reported that they were much more or somewhat more likely to use the internet post-training cited a higher comfort level with the internet as the reason for greater internet use. In contrast, only 44 percent of younger adults in the training program identified greater comfort post-training as a reason for greater internet use.

\section{The impact of ageism on the digital divide}

Extending the existing literature on technology adoption, we suggest that an additional reason for the digital divide among older adults is that some older adults have internalized the negative messages of ageism.

Expanding the self-efficacy concept, ageism may lead to a reduction in self-efficacy among older adults if they internalize society's negative perception of older adults, and specifically older adults' inability to use internet technology. Older adults with such lower self-efficacy will have higher psychic costs of internet use because they are fearful and anxious about their ability to use the internet successfully. These increased psychic costs of internet use may reduce their demand for internet service.

The Technology Acceptance Model (TAM) focuses on intent to use technology, which is influenced by a user's belief about the technology's perceived usefulness and perceived ease of use. Ageism may cause some older adults to underestimate the usefulness of the internet. If ageism contributes to internet anxiety, older adults may rationalize: I have functioned very well without the internet and thus the internet will not be useful to me. Usefulness requires successful execution of an internet-related task. Ageism may also affect the perceived ease of use of the internet, because ageism depicts older adults as lacking the ability to adapt to new ideas and specifically, to use the internet. If ageism contributes to the perception that the internet is hard for older adults to use, then older adults will be less likely to use the internet because they feel their efforts might be futile or embarrassing.

According to the Technology Readiness (TR) model, a person's propensity to use new technology has four dimensions: optimism, innovativeness, discomfort, and insecurity. Each of these dimensions may be impacted by the negative messages of ageism. Ageism may reduce an older adult's optimism about the successful use of internet technology, because ageism's message is that older adults are not internet-competent. Ageism may also diminish an older adult's innovative attitude toward technology: some older adults may internalize the external message that older adults are inflexible and cannot learn new things. Furthermore, ageism may cause or intensify some older adults' feelings of discomfort with, and mistrust of, the internet.

The concept that ageism contributes to the digital divide fits well within the Technology Readiness and Acceptance Model (TRAM). According to TRAM's findings, older adults who view themselves as technologically incompetent may devalue the benefits and usefulness of the internet. Some older adults may internalize ageism's negative message that older adults are internet-incompetent. As a result, these older adults devalue the benefits of the internet and consequently do not adopt the internet or do not fully utilize its benefits.

The survey results discussed above identify attitude toward the internet, and comfort levels, as significant determinants of internet adoption among older adults. Certainly factors such as resistance to new technologies and preference for a more personal mode of communication may inform an older adult's negative attitude toward the internet. Ageism may also affect older adults' attitudes. Ageism fosters the image of older adults as being internet-averse and internet-incompetent. Some older adults, in a form of the bandwagon effect, may come to believe that their negative attitude toward the internet is a typical and appropriate attitude for older adults. Such a conclusion would reduce an older adult's willingness to adopt the internet. For similar reasons, ageism may contribute to an older adults' lack of comfort with internet technology.

\section{Concluding remarks}

Is the age-related digital divide in internet usage a reaction of older generations to historical change ${ }^{24}$, or an age-related decrease per se in internet use? The current senior cohort grew up at a time when the

23 - 335 older adults responded to the survey question about pre-training internet use 24 - Czaja [27] 
internet was not available. As today's younger cohorts age, they will have the advantage of having grown up using the internet ${ }^{25}$. This argument leads to the likelihood that the digital divide is caused by this historical factor and can be expected to diminish or fade over time.

However, software and hardware design and functionalities are continually being updated and revised, with older technologies rendered obsolete. This makes a willingness and ability to learn new technologies necessary for continuing internet use. Physical and cognitive limitations may have a negative impact on next-generation older adults' adoption of new technologies. Ageism compounds this problem. Younger adults as they age may internalize negative perceptions about older adults and therefore doubt their ability to adopt new, more complex, internet technologies. The result will be a continuing digital divide. Future research will examine empirically the magnitude of the impact of ageism on the digital divide among older adults.

\section{References}

1. Hetzner S, Tenckhoff-Eckhardt A, Slyschak A, Held P (2012) Promoting digital literacy for seniors, the aptitude of tablet-pcs. eLearning papers 38: 1-12.

2. United States Census Bureau (2013) American Community Survey Report United States Census Bureau, USA

3. van Deursen, Alexander, Helsper, Ellen (2015) A nuanced understanding of Internet use and non-use amongst older adults. Eur J Communn.

4. Broadband Expanded (2012) Broadband and Senior Citizens. Broadband Expanded, USA.

5. Zickuhr K, Smith A (2013) Home Broadband 2013. Pew Research Center, Washington DC, USA.

6. Smith A (2014) Older adults and technology use. Pew Research Center, Washington DC, USA.

7. Erb R (2014) Teaching seniors to use Internet cuts depression risk. Detroit Free Press, Detroit, MI, USA.

8. Harrington TL, Harrington MK (2000) Gerontechnology: Why and How. Herman Bouma foundation for gerontechnology, Eindhoven, Maastricht, the Netherlands.

9. van Bronswijk JEMH, Bouwhuis DG, Fozard, JL, Bouma H (2008) Gerontechnology Basics. Gerontechnology 7: 80.

10. Wu YH, Damnée S, Kerhervé H, Ware C, Rigaud AS (2015) Bridging the digital divide in older adults: a study from an initiative to inform older adults about new technologies. Clin Interv Aging 10: 193-200.

11. Bamidis PD, Fissler P, Papageorgiou SG, Zilidou V, Konstantinidis El, et al. (2015) Gains in cognition through combined cognitive and physical training the role of training dosage and severity of neurocognitive disorder. Front $\mathrm{Ag}$ ing Neurosci 7: 152.

12. Horrigan JB (2010) Broadband Adoption \& Use in America: Results from an FCC Survey. Federal Communications Commission, Washington, DC, USA.

13. Donat E, Brandtweiner R, Kerschbaum J (2009) Attitudes and the Digital Divide: Attitude Measurement as Instrument to Predict internet Usage. Informing Science: the International Journal of an Emerging Transdiscipline 12 $38-56$.

14. Porter CE, Donthu N (2006) Using the technology acceptance model to explain how attitudes determine internet usage: The role of perceived access barriers and demographics. Journal of Business Research 59: 999-1007.
15. Butler RN (1969) Age-ism: another form of bigotry. Gerontologist 9: 243-246.

16. Butler RN (2008) The Longevity Revolution: The Benefits and Challenges of Living A Long Life. Public Affairs (Perseus Book Group) New York, USA.

17. Palmore E (1999) Ageism: Negative and Positive. (2ndedn), Springer Publishing Company, New York, USA.

18. Palmore E (2001) The ageism survey: first findings. Gerontologist 41: $572-$ 575

19. Keita GP (2014) Speaking up against ageism. In the public interest 45: 61

20. Aosved AC, Long PJ, Voller EK (2009) Measuring Sexism, Racism, Sexual Prejudice, Ageism, Classism, and Religious Intolerance: The Intolerant Schema Measure. Journal of Applied Social Psychology 39: 2321-2354.

21. Cherry KE, Allen PD, Denver JY, Holland KR (2015) Contributions of Social Desirability to Self-Reported Ageism. J Appl Gerontol 34: 712-733.

22. Argentum (2015) Ageism. Argentum, Alexandria, VA, USA.

23. Neves BB, Amaro F (2012) Too old for technology? How the elderly of Lisbon use and perceive ICT. The Journal of Community Information 8: 1-12.

24. Levy B (2009) Stereotype Embodiment: A Psychosocial Approach to Aging. Curr Dir Psychol Sci 18: 332-336.

25. Stigler, Stigler GJ (1966) The Theory of Price. Prentice Hall, New Jersey, USA.

26. Becker GS (1976) The Economic Approach to Human Behavior. The University of Chicago Press, Chicago, IL USA.

27. Czaja SJ, Charness N, Fisk AD, Hertzog C, Nair SN, et al. (2006) Factors predicting the use of technology: findings from the Center for Research and Education on Aging and Technology Enhancement (CREATE). Psychol Aging 21: 333-352.

28. Nielsen L, Elias J, Phillips J (2005) Neuroeconomics and Aging. National Institute on Aging. National Institutes of Health, USA.

29. Rogers EM (1962) Diffusion of Innovations. (5thedn), Free Press, New York, USA

30. Roalf DR, Mitchell SH, Harbaugh WT, Janowsky JS (2012) Risk, reward, and economic decision making in aging. J Gerontol B Psychol Sci Soc Sci 67: 289-298.

31. Zeithaml VA (1988) Consumer perceptions of price, quality, and value: a means-end model and synthesis of evidence. Journal of Marketing, American Marketing Association 52: 2-22.

32. Bandura A (1977) Self-efficacy: toward a unifying theory of behavioral change. Psychol Rev 84: 191-215.

33. Davis FD (1989) Perceived usefulness, perceived ease of use, and user acceptance of information technology. MIS Quarterly, Minneapolis, MN, USA 13: $319-340$

34. Lin C-H, Shih, Shih H-Y, Sher PJ (2007) Integrating technology readiness into technology acceptance: the tram model. Psychology \& Marketing 24 641-657.

35. McDonough C (2013) Annual performance progress report for sustainable broadband adoption. Department of Commerce, National Telecommunications and Information Administration, University of Massachusetts Lowell, Lowell, MA, USA.

36. Morris MG, Venkatesh V (2000) Age differences in technology adoption decisions: implications for a changing work force. Personnel Psychology 53 : 375-403.

25 - Morris and Venkatesh [36] discuss how younger workers, having grown up in the compute age, are more likely to make independent judgments about technology and less likely to depend on opinions of co-workers. 
37. Parasuraman A (2000) Technology readiness index (TRI): A multiple-item scale to measure readiness to embrace new technologies. Journal of Service Research 2: 307-320.

38. Zheng R, Spears J, Luptak M, Wilby F (2015) Understanding older adults' perceptions of internet use: an exploratory factor analysis. Educational Gerontology 41: 504-518.

39. Bandura A (1977) Self-efficacy: toward a unifying theory of behavioral change. Psychol Rev 84: 191-215.

40. MacLeod C (1996) Anxiety and Cognitive Processes. In: Cognitive Interference: Sarason IG, Pierce GR, Sarason BR (eds.). Cognitive Interference: Theories, methods, and findings, Routledge Taylor \& Francis group, New York, USA. Pg no: 47-76.

41. Ellis D, Allaire JC (1999) Modeling computer interest in older adults: the role of age, education, computer knowledge, and computer anxiety. Hum Factors 41: 345-355.
42. Brosnan MJ (1999) Modeling technophobia: a case for word processing Computers in human behavior 15: 105-121.

43. Venkatesh V, Bala H (2008) Technology Acceptance Model 3 and a Research Agenda on Interventions. Decision Sciences 39: 273-315.

44. Lu J, Yu C-H, Liu C, Yao JE (2003) Technology acceptance model for the wireless Internet. Internet Research 13: 206-222.

45. Umemuro $\mathrm{H}$ (2004) Computer attitudes, cognitive abilities and technology usage among older Japanese adults. Gerontechnology 3: 64-76.

46. McDonough C, Kingsley D (2015) The impact of mobile broadband on the digital divide affecting older adults. International Telecommunications Policy Review 22: 27-42. 